AWEJ for Translation \& Literary Studies, Volume3, Number4. October 2019

Pp. 24-35

DOI: http://dx.doi.org/10.24093/awejtls/vol3no4.3

\title{
Elevating Social Status by Racial Passing and White Assimilation: in George Schuyler's Black No More
}

\author{
Menia Mohammad Almenia \\ Department of English Language and Translation \\ College of Arabic Language and Social Sciences \\ Qassim University, Buraidah, Saudi Arabia
}

\begin{abstract}
:
This paper examines the legacy of the 1932 novel Black No More by George Schuyler with its message promoting assimilation. Racial divisions within the United States have a complex history, either insisting on separation or promoting unity, but advocates of assimilation have traditionally been viewed negatively. This paper aims to reconcile the assimilationist views of Schuyler against his larger purpose of empowerment through change. Schuyler focuses on issues of education, economy, and social status to demonstrate his thesis: meaningful change is possible if action is taken. Numerous theorists such as Jane Kuenz (1997), Hee-Jung Serenity Joo (2008), Jason Haslam (2002), and Ann Rayson (1978) have considered that Schuyler as an assimilationist. Schuyler's novel builds a case for assimilation of individuals into the dominant culture as the practical course for improvement on both a personal and social scale.
\end{abstract}

Keywords: assimilation, Black No More, empowerment, Harlem Renaissance, passing, race, Schuyler, whiteness

Cites as: Almenia, M. M. (2019). Elevating Social Status by Racial Passing and White Assimilation: in George Schuyler's Black No More. Arab World English Journal for Translation \& Literary Studies3 (4) 24-35. DOI: http://dx.doi.org/10.24093/awejtls/vol3no4.3 